ISSN 0103-9954

\title{
CRESCIMENTO INICIAL DE MUDAS DE ERVA-MATE (Ilex paraguariensis St. Hil.) EM TRÊS CLASSES DE SOLOS, NA REGIÃO CENTRAL DO RIO GRANDE DO SUL ${ }^{1}$
}

\section{INITIAL GROWTH OF “ERVA-MATE” (Ilex paraguariensis St. Hil.) SEEDLINGS IN THREE SOIL TYPES IN CENTRAL REGION OF RIO GRANDE DO SUL STATE}

\author{
Fabio Luiz Fleig Saidelles ${ }^{2}$ Dalvan José Reinert ${ }^{3} \quad$ Roberto Luiz Salet ${ }^{4}$
}

\section{RESUMO}

O experimento foi instalado em três sítios, com condições climáticas semelhantes e com diferentes classes de solos. Foram usados diferentes tratamentos de adubação para o plantio das mudas de erva-mate, visando ao estudo de efeito destes sobre o seu crescimento inicial. Os sítios apresentam solos classificados como Plintossolo Argilúvico, Alissolo Cromico e Neossolo Litólico, sendo que os tratamentos foram: vermicomposto, tratamento sem fertilizante, $1 / 2$ dose recomendada de N-P-K e a dose recomendada de N-PK. O crescimento inicial foi avaliado medindo-se o incremento absoluto em altura, área foliar total e número de folhas da planta, em quatro períodos, durante o primeiro ano. Também, foi avaliado o percentual de plantas sobreviventes cinco meses após o plantio das mudas. A fertilização química reduziu o número de plantas sobreviventes, enquanto que, o uso de vermicomposto e o tratamento sem fertilizantes no plantio induziram maior sobrevivência e maior altura das plantas. Não houve diferença na área foliar e número de folhas para as formas de adubação no plantio. O maior incremento na área foliar total e no número de folhas foi observado no sítio com solo raso e com maior fertilidade natural, o Neossolo Litólico.

Palavras-chave: erva-mate, classe de solo, fertilizante, crescimento inicial.

\begin{abstract}
The experiments were installed in three sites with different soil classes but with similar climatic conditions using different fertilization treatment to study initial plant growth of "Erva-mate". The sites were located on an Entisol and two Alfisols and plantation was perfomed using organic compost, no fertilizer, one half and full dosage of N-P-K recommended. The initial growth was evaluated measuring absolute increment in plant height, total plant leaf area and plant leaf number at four times during the first year. The experiments were installed in September of 1998 and in February 1, 1999 plant survival was measured. Chemical fertilization reduced the final survival, whereas, the use of $1 \mathrm{~kg}$ of organic compost and nofertilization at planting induced higher plant stand and initial growth as measured by absolute increment in total plant leaf area and height. There was a significant effect of soil type, where, the higher increment in total leaf area and leaf number was observed at the site with shallow and naturally most fertile soil, the Entisol.
\end{abstract}

Key words: erva-mate, soil classes, fertilizer, initial growth.

\section{INTRODUÇÃO}

A erva-mate, pela sua importância sociocultural e econômica, foi oficialmente escolhida como a árvore símbolo do estado do Rio Grande do Sul. O desmatamento, ocorrido para a introdução da agricultura em muitas áreas, causou a degradação de povoamentos dessa essência, fazendo com que fossem necessários plantios homogêneos para suprir a necessidade crescente de consumo. Com esses plantios, aumentou a demanda por tecnologia de produção da espécie.

A área de distribuição natural da erva-mate, segundo Oliveira e Rotta (1985), abrange aproximadamente de $540.000 \mathrm{~km}^{2}$, cerca de 3\% do território da América do Sul, compreendendo áreas do

1. Parte da dissertação de mestrado do primeiro autor, apresentada ao Programa da Pós-graduação em Engenharia Florestal, Universidade Federal de Santa Maria.

2. Engenheiro Florestal, M.Sc., Caixa Postal 322, CEP 97001-970, Santa Maria (RS). ffleig@yahoo.com.br

3. Engenheiro Agrônomo, Dr., Professor Titular do Departamento de Solos, Centro de Ciências Rurais, Universidade Federal de Santa Maria, CEP 97105-900, Santa Maria (RS). dalvan@,ccr.ufsm.br

4. Engenheiro Agrônomo, Dr., Pólo de Modernização Tecnológico do alto do Jacuí e Professor da UNICRUZ, Universidade de Cruz Alta, Caixa Postal 858, CEP 98025-810, Cruz Alta (RS).

Recebido para publicação em 18/04/2001 e aceito em 3/09/2003. 
Brasil, Argentina e Paraguai, situadas entre as latitudes de $21^{\circ} \mathrm{S}$ a $30^{\circ} \mathrm{S}$ e longitudes de $48^{\circ} 30^{\prime} \mathrm{W}$ a $56^{\circ}$ $10^{\prime} \mathrm{W}$. Cresce preferencialmente em altitudes compreendidas entre 500 e $1.500 \mathrm{~m}$, podendo ocorrer em regiões situadas fora desses limites, porém de maneira mais esparsa. Para os autores condições climáticas para o ótimo desenvolvimento da espécie, segundo a classificação climática descrita por Köppen, está nos tipos climáticos $\mathrm{Cfb}$, seguido pelo Cfa.

A erva-mate vegeta preferencialmente em solos úmidos e permeáveis, não ocorrendo em solos hidromórficos, nem em solos que possuem deficiência hídrica. A espécie é considerada tolerante a solos de baixa fertilidade natural, resistindo a solos degradados, sendo mais freqüente em solos com baixo teor de nutrientes trocáveis e alto teor de alumínio. Sua presença é mais freqüente em solos de texturas médias (entre 15 e 35\% de argila) e argilosa (mais de 35\%), sendo raramente encontrada em solos constituídos por areias quartzosas (abaixo de 15\% de argila). Tem ocorrência esparsa em solos rasos, preferindo solos medianamente profundos a profundos (Oliveira e Rotta, 1985).

Os solos mais indicados para o cultivo da erva-mate na Argentina, são os LATOSSOLOS VERMELHOS (Rodochrult órtico), muito intemperizados, lixiviados, argilosos, permeáveis (infiltração média de $1200 \mathrm{~mm} \mathrm{~h}^{-1}$ ), ácidos ou ligeiramente ácidos, medianamente férteis, derivados do basalto (Prat Kricun, 1985). O autor relata o plantio em solos do complexo 6 (Haplumbret e Dystrochrept) que são solos jovens, ligeiramente ácidos, permeáveis (infiltração média de $800 \mathrm{~mm} \mathrm{~h}^{-1}$ ) e férteis, desde que estes apresentem profundidade mínima de $1 \mathrm{~m}$.

Estudo realizado na Argentina, utilizando diferentes combinações de nitrogênio, fósforo e potássio, Prat Kricun (1985) após 5 anos de experiências, observou que o nitrogênio foi o mais eficiente, seguido do fósforo e do potássio. Posteriormente, o autor testou uma dose fixa de $\mathrm{N}$ com doses crescentes de $\mathrm{K}$ e $\mathrm{P}$ em que observou que todas as proporções de $\mathrm{K}$ e $\mathrm{P}$ superaram a testemunha, mas não houve diferença entre as dosagens.

Por outro lado, trabalho realizado em um LATOSSOLO VERMELHO do Planalto do Rio Grande do Sul observou que a erva-mate não respondeu à adubação fosfatada (Bisso e Salet, 1998).

As recomendações de adubação da erva-mate, para o Rio Grande do Sul e Santa Catarina, determinam que a adubação nitrogenada no plantio deve ser: a) $60 \mathrm{~kg}$ de $\mathrm{N} \mathrm{ha}^{-1}$, quando o teor de matéria

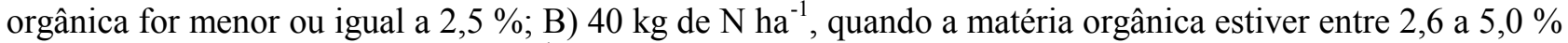
e; c) menor ou igual a $20 \mathrm{~kg}$ de $\mathrm{N} \mathrm{ha}^{-1}$, quando a matéria orgânica for maior de 5,0 \%. A adubação fosfatada no plantio da erva-mate deve ser baseada no P do solo: a) quando for limitante deve-se aplicar $130 \mathrm{~kg} \mathrm{P}_{2} \mathrm{O}_{5}$ $\mathrm{ha}^{-1}$; b) muito baixo aplicam-se $90 \mathrm{~kg} \mathrm{P}_{2} \mathrm{O}_{5} \mathrm{ha}^{-1}$; c) baixo, aplicam-se $60 \mathrm{~kg} \mathrm{P}_{2} \mathrm{O}_{5} \mathrm{ha}^{-1}$; d) médio aplicam-se $40 \mathrm{~kg} \mathrm{P}_{2} \mathrm{O}_{5} \mathrm{ha}^{-1}$; e) suficiente aplicam-se $20 \mathrm{~kg} \mathrm{P}_{2} \mathrm{O}_{5} \mathrm{ha}^{-1} \mathrm{e}$; e) alto aplicam-se $20 \mathrm{~kg} \mathrm{P}_{2} \mathrm{O}_{5} \mathrm{ha}^{-1}$. A adubação potássica no plantio baseiam-se no $\mathrm{K}$ disponível do solo: a) quando for limitante, aplicam-se $50 \mathrm{~kg} \mathrm{~K}_{2} \mathrm{O} \mathrm{ha}^{-}$ ${ }^{1}$; b) muito baixo aplica-se $40 \mathrm{~kg} \mathrm{~K}_{2} \mathrm{O} \mathrm{ha}^{-1}$; c) baixo aplica-se $30 \mathrm{~kg} \mathrm{~K}_{2} \mathrm{O}$ ha ${ }^{-1}$; d) médio aplica-se $20 \mathrm{~kg} \mathrm{~K}_{2} \mathrm{O}$ $\mathrm{ha}^{-1}$; e) suficiente aplica-se $10 \mathrm{~kg} \mathrm{~K}_{2} \mathrm{O} \mathrm{ha}^{-1}$ e; f) alto aplica-se $10 \mathrm{~kg} \mathrm{~K}_{2} \mathrm{O} \mathrm{ha}{ }^{-1}$. Observa-se que a adubação de plantio deve ser aplicada na coroa ou no sulco de plantio na instalação do povoamento (COMISSÃO DE FERTILIDADE DO SOLO RS/SC, 1994).

A adubação de plantio pode ser corretiva da área toda ou parte dela, ou adubação de arranque, na cova, onde se procura auxiliar a adaptação das mudas às condições de campo. Bons plantios têm sido observados com adição de $60 \mathrm{~g}$ de um adubo NPK na fórmula 10-20-10, mais aproximadamente, $1 \mathrm{~kg}$ de esterco orgânico (de gado, ovelha ou suíno). Também, são muitos os bons ervais que não receberam adubação mineral no plantio. (Lourenço, 1997).

As exigências e tolerâncias quanto às condições de solos, para o cultivo da erva-mate, são pouco conhecidas. Grandes variações de crescimento e produtividade são observadas quando se cultiva a erva-mate em diferentes tipos de solos. A maioria das pesquisas existentes, sobre o desenvolvimento da erva-mate, referem-se a solos onde a ocorrência da espécie já é natural. Também, a fertilização nos ervais não possui critérios definidos e, geralmente, baseia-se no senso comum. Considerando essa problemática acima, os objetivos deste trabalho foram de:

Ciência Florestal, v. 13, n. 2, 2003 
a) Avaliar o crescimento inicial da erva-mate em 3 classes de solos, considerados marginais para a cultura, na região da Depressão Central do estado do RS.

b) Avaliar a resposta no crescimento da cultura da erva-mate a duas doses de adubo químico e uma dose de vermicomposto nos três sítios.

c) Analisar o efeito das formas de adubação e dos sítios sobre o número de plantas sobreviventes.

\section{MATERIAL E MÉTODOS}

O presente trabalho foi realizado em três áreas da região central do Estado, formando três sítios caracterizados a seguir.

\section{Sítio 1 - Plintossolo argilúvico distrófico arênico}

Este solo localiza-se no Campus da UFSM, em Santa Maria, RS, sendo um solo profundo, bem drenado, horizonte Ap com espessura de $23 \mathrm{~cm}$ e textura franco arenosa ( $7 \%$ argila e $73 \%$ areia).

De acordo com a classificação climática de Köppen, a área enquadra-se num clima temperado chuvoso e quente, do tipo Cfa. O índice de precipitação é de 1.500 a $1.700 \mathrm{~mm}$, distribuídos regularmente durante o ano, sendo os meses de novembro, dezembro e março os menos chuvosos, quando podem ocorrer déficits hídricos, com danos às plantas cultivadas (Sartori, 1979).

\section{Sítio 2 - Alissolo cromico argilúvico típico}

Este solo localiza-se no Campus da UFSM, em Santa Maria, RS, horizonte Ap com espessura de $18 \mathrm{~cm}$ e textura franco argilosa (18\% argila e 36\% areia).

A classificação climática da área é semelhante a do sítio 1.

\section{Sítio 3 - Neossolo litólico psamítico típico}

Este solo localiza-se em São João do Polêsine, RS. sendo um solo que caracterizou presença do horizonte A e R com rocha bem intemperizada, horizonte Ap com espessura de $15 \mathrm{~cm}$ e textura franco arenosa ( $8 \%$ argila e $69 \%$ "areia).

A classificação climática da área é a mesma do sítio 1.

Foram retiradas amostras de 0 a $20 \mathrm{~cm}$, representativas das três classes de solo, para fins de recomendação de adubação e remetidas para o laboratório de análises de solos da UFSM, vinculado à rede de laboratórios de SC e RS. Com base nos resultados obtidos (Tabela 1), foram realizadas as recomendações de adubação (NPK) de acordo com a COMISSÃO DE FERTILIDADE DO SOLO RS/SC (1994), para a cultura da erva-mate.

O plantio foi realizado em 23/09 no sítio 1, 25/09 no sítio 2 e 8/10 no sítio 3, durante o ano de 1998 . Nos três sítios, o plantio foi realizado em área gradeada, com posterior coveamento com enxada no momento do plantio. As mudas foram protegidas contra a ação dos raios do sol poente, com uso de lâminas de madeira. O espaçamento utilizado foi $1,0 \mathrm{~m}$ na linha e de $3,0 \mathrm{~m}$ na entrelinha. E receberam tratos culturais semelhantes, para controle de plantas daninhas. Na linha de plantio, a área recebeu duas aplicações de dessecante e uma roçada com roçadeira costal. Para controle nas entrelinhas, foram realizadas quatro roçadas com trator.

Os tratamentos foram os seguintes:

Fator A1 - Sítio 1;

Fator A2 - Sítio 2;

Fator A3 - Sítio 3;

Fator B1 - adubação na cova, com adubo orgânico, vermicomposto de feses bovina $1 \mathrm{Kg}(\mathrm{T} 1)$;

Fator B2 - tratamento testemunha, sem adubação (T2);

Fator B3 - adubação na cova, com metade da dose de NPK recomendada pela COMISSÃO DE FERTILIDADE DO SOLO RS/SC (1994) (T3);

Fator B4 - adubação na cova, com a dose integral de NPK recomendada pela COMISSÃO DE FERTILIDADE DO SOLO RS/SC (1994) (T4). 
Os resultados das análises químicas do vermicomposto usado no tratamento 1 foram: $\mathrm{pH}=6,7 ; \mathrm{C} \%$ $=15,77 ; \mathrm{N} \%=0,88 ;$ relação $\mathrm{C} / \mathrm{N}=17,92 ; \mathrm{P} \%=0,373 ; \mathrm{K} \%=0,550 ; \mathrm{Ca} \%=0,550 ; \mathrm{Mg}_{0}=0,270$.

Para a análise dos efeitos dos tratamentos no crescimento, foram numeradas cinco plantas por parcela nas quais foram avaliadas as seguintes variáveis com respectivas abreviaturas, unidades e forma de mensuração:

a) Altura das Plantas - A (cm): medidas com régua, com precisão de $0,1 \mathrm{~cm}$, do colo da planta até a última inserção de folha.

b) Área Foliar - AF $\left(\mathrm{cm}^{2}\right)$ : das cinco plantas escolhidas por parcela, foram medidos o comprimento e a maior largura de todas as folhas, usando a equação $\mathrm{AF}=\mathrm{C} \times \mathrm{L}$ x ff (ff $=$ fator de forma que variou de 0,65 a 0,72 ) estimou-se a área foliar. A AF total por planta foi obtido pelo somatório das AF de cada folha.

c) Número de Folhas - NF (un): foi obtido diretamente pela contagem do número de folhas das cinco plantas por parcela.

d) Percentagem de Plantas Sobreviventes por Parcela - PPS (\%): o levantamento das plantas sobreviventes foi realizado em primeiro de fevereiro de 1999, considerando as plantas da parcela útil.

Para avaliação do crescimento, as variáveis altura, área foliar e número de folhas foram analisadas pelo incremento que apresentaram no período médio entre a primeira e as demais medições.

Foram feitas análises das variâncias dos parâmetros de crescimento, segundo o delineamento blocos ao acaso, para um experimento bifatorial com quatro repetições. As diferenças entre as médias foram determinadas pelo Teste de Duncan a 5\% de probabilidade.

TABELA 1: Resultado da análise química dos três solos realizada pelo Laboratório Central de Análises de Solo da UFSM.

TABLE 1: Result of the chemical analysis of three soils carried through by Laboratory of Soil Analysis of UFSM.

\begin{tabular}{|c|c|c|c|c|c|c|c|c|c|c|}
\hline Sítio & Textura & $\begin{array}{c}\% \text { argila } \\
\mathrm{m} / \mathrm{v}\end{array}$ & $\begin{array}{c}\mathrm{pH}-\mathrm{H}_{2} \mathrm{O} \\
1: 1\end{array}$ & $\begin{array}{l}\text { Índice } \\
\text { SMP }\end{array}$ & \multicolumn{2}{|c|}{$\begin{array}{c}\mathrm{P} \\
\mathrm{mg} / \mathrm{L}\end{array}$} & \begin{tabular}{|c|}
$\mathrm{K}$ \\
$\mathrm{mg} / \mathrm{L}$
\end{tabular} & $\begin{array}{c}\% \mathrm{MO} \\
\mathrm{m} / \mathrm{V}\end{array}$ & $\begin{array}{c}\mathrm{Al} \\
\mathrm{cmol} / \mathrm{L}\end{array}$ & $\begin{array}{c}\mathrm{Ca} \\
\mathrm{cmol} / \mathrm{L}\end{array}$ \\
\hline 1 & 4 & 15 & 5,2 & 5,8 & \multicolumn{2}{|c|}{3,2} & 74 & 1,5 & 1,0 & 1,0 \\
\hline 2 & 4 & 17 & 5,3 & 5,7 & \multicolumn{2}{|c|}{4,0} & 34 & 2,4 & 0,6 & 3,5 \\
\hline 3 & 4 & 17 & 6,0 & 6,1 & \multicolumn{2}{|c|}{7,2} & 200 & 2,6 & 0,0 & 15,0 \\
\hline Sítio & $\mathrm{Mg}$ & $\mathrm{H}+\mathrm{Al}$ & CTC-ef. & CTC-pH7 & \multicolumn{2}{|c|}{ Saturação \% } & K/ & $\mathrm{Ca} / \mathrm{Mg}$ & $\mathrm{Ca} / \mathrm{K}$ & $\mathrm{Mg} / \mathrm{K}$ \\
\hline & $\mathrm{cmol} / \mathrm{L}^{-1}$ & $\mathrm{cmol} / \mathrm{L}^{-1}$ & $\mathrm{cmol} / \mathrm{L}^{-1}$ & $\mathrm{cmol} / \mathrm{L}^{-1}$ & $\mathrm{Al}$ & Bases & $\mathrm{Ca}+\mathrm{Mg}$ & & & \\
\hline 1 & 0,6 & 4,3 & 2,8 & 6,1 & 35,8 & 29,5 & 0,150 & 1,7 & 5 & 3 \\
\hline 2 & 1,7 & 4,7 & 5,9 & 10,0 & 10,2 & 53,1 & 0,038 & 2,1 & 40 & 20 \\
\hline 3 & 4,3 & 3,3 & 19,3 & 23,1 & 0,0 & 85,9 & 0,117 & 3,5 & 29 & 8 \\
\hline
\end{tabular}

\section{RESULTADOS E DISCUSSÃO}

\section{Sobrevivência das plantas}

O sítio 1 apresentou maior percentagem de plantas sobreviventes (Tabela 2) em relação aos demais. O sítio 1 possui solo arenoso no qual é fácil misturar o adubo e realizar o plantio. O sítio 2 apresenta solo com mais silte e argila, sendo mais consistente, formando torrões maiores quando gradeado.

Os sítios 1 e 2 receberam 56,5 mm de precipitação quatro dias após o plantio. Tais fatos indicam provável efeito positivo da precipitação no sítio 1 e negativo pelo entorroamento no sítio 2 na sobrevivência das plantas. Embora o sítio 3 não tenha apresentado a formação de torrões que impedissem uma boa mistura do adubo à terra e plantio, teve as suas mudas prejudicadas pela falta de precipitação, somente ocorrida 15 dias após o plantio.

TABELA 2: Número de plantas de erva mate sobreviventes (NPS) e percentagem de plantas sobreviventes

Ciência Florestal, v. 13, n. 2, 2003 
(PPS) para os três sítios.

TABLE 2: Number (NPS) and percentage (PPS) of surviving erva-mate plants for the theree sites.

\begin{tabular}{c|c|c}
\hline Sítios & NPS $\left(\mathrm{n}^{\mathrm{o}}\right)$ & PPS (\%) \\
\hline 1 & $22 \mathrm{a}$ & $64 \mathrm{a}$ \\
2 & $19 \mathrm{ab}$ & $52 \mathrm{~b}$ \\
3 & $18 \mathrm{~b}$ & $51 \mathrm{~b}$ \\
\hline
\end{tabular}

Em que: médias seguidas de mesma letra são estatisticamente iguais pelo teste de Duncan a $5 \%$ de probabilidade; NPS = número de plantas sobreviventes; PPS = percentagem de plantas sobreviventes.

A percentagem de sobrevivência das plantas, no tratamento testemunha, foi superior aos demais tratamentos (Tabela 3), sendo os piores, os tratamentos constituídos de doses de adubos químicos, não apresentando diferença entre si. O efeito da adubação, na sobrevivência das plantas, foi associado à formação de torrões no solo o que dificulta a mistura do adubo com a terra usada para sustentar a muda. Associado a esse fator, deve-se destacar ainda que a baixa precipitação ocorrida após o plantio pode ter acentuado o efeito da salinidade do adubo, o que pode ter provocado a morte das mudas. Esse fenômeno é mais marcante na primavera/verão, quando foram plantadas as mudas de erva-mate.

TABELA 3: Número de plantas de erva-mate sobreviventes e percentagem de plantas sobreviventes para as quatro formas de adubação no plantio da erva-mate.

TABLE 3: Number and percentage of surviving erva-mate plants for the form types of fertilization.

\begin{tabular}{|c|c|c|}
\hline Tratamentos & NPS & PPS \\
\hline T1- Vermicomposto & $26 \mathrm{~b}$ & $72 b$ \\
\hline T2- Testemunha & $32 \mathrm{a}$ & $88 \mathrm{a}$ \\
\hline T3-1/2 Dose NPK & $12 \mathrm{c}$ & $32 \mathrm{c}$ \\
\hline T4- 1 Dose NPK & $10 \mathrm{c}$ & $30 \mathrm{c}$ \\
\hline
\end{tabular}

Em que: médias seguidas de mesma letra, são estatisticamente iguais pelo teste de Duncan a 5\% de probabilidade; NPS = número de plantas sobreviventes; PPS = percentagem de plantas sobreviventes.

Também, podemos observar, nesta tabela, que o tratamento com vermicomposto teve menor perda de plantas que os tratamentos com adubação química, porém, com maiores perdas de plantas que o tratamento sem adubação.

\section{Análise do crescimento}

Incremento em altura - IA

Não houve interação significativa a 5\% entre sítio e tratamento para as variáveis de crescimento em todas medições.

O incremento em altura, entre a primeira e a segunda medição (IA 2), no sítio 1, foi superior aos demais sítios, sendo que o sítio 2 e 3 não diferiram entre si. (Tabela 4).

TABELA 4: Incremento em altura (IA) de mudas de erva-mate para os sítios estudados, em três épocas de medição.

TABLE 4: Increment in height (IA) of erva-mate for the studied sites, at three times of measurement.

\begin{tabular}{c|c|c|c}
\hline \multirow{2}{*}{ Sítio } & IA 2 $(\mathrm{cm})$ & IA 3 (cm) & IA 4 (cm) \\
\cline { 2 - 4 } & \multicolumn{3}{c}{$(\mathrm{cm})$} \\
\hline 1 & $21,1 \mathrm{a}$ & $21,2 \mathrm{a}$ & $29,7 \mathrm{a}$ \\
2 & $16,5 \mathrm{~b}$ & $16,8 \mathrm{~b}$ & $26,4 \mathrm{a}$ \\
3 & $17,7 \mathrm{~b}$ & $19,8 \mathrm{a}$ & $31,6 \mathrm{a}$ \\
\hline
\end{tabular}

Em que: médias seguidas de mesma letra, na vertical, não diferem estatisticamente pelo teste de Duncan a $5 \%$ de probabilidade. IA $2=$ Incremento entre a $1^{\text {a }}$ e a $2^{\mathrm{a}}$ medição; IA $3=$ Incremento entre a $1^{\mathrm{a}}$ e a $3^{\mathrm{a}}$ medição; IA $4=$ Incremento entre a $1^{\mathrm{a}}$ e a $4^{\mathrm{a}}$ medição.

Na comparação dos crescimentos médios entre a medição um e três (IA 3), não foi constatada diferença entre os sítios 1 e 3, apresentando-se superiores ao 2. O crescimento em altura na época 3 (IA 3), em relação à segunda medição, indica que as plantas não aumentaram em altura, nesse período, nos sítios $1 \mathrm{e}$ 2. No sítio 3, houve pequeno acréscimo de altura nesse período. Resultados semelhantes foram encontrados

Ciência Florestal, v. 13, n. 2, 2003 
por Pintro (1986) que verificou que as plantas apresentaram menores acréscimos em altura no período de inverno, associando a diminuição das atividades do tecido meristemático, ocasionada pelas baixas temperaturas.

Na comparação da média dos incrementos em altura entre a primeira e a quarta medição (IA 4) não houve diferenças significativas entre os sítios. Os incrementos de altura do dia 25 de dezembro de 1998 (primeira medição) até 10 de dezembro de 1999 foram de $29,7 \mathrm{~cm}, 26,4 \mathrm{~cm}$ e 31,6 cm, respectivamente, para ao sítio $1,2,3$.

O maior incremento na altura, embora não-significativo estatisticamente, das plantas ocorrem no sítio 3, considerando todo o período analisado e parece estar mais fortemente relacionado com a melhor fertilidade natural desse solo, em relação aos outros dois e à boa capacidade de retenção de água e boa capacidade de aeração das raízes apresentada pelo solo desse sítio apesar da sua pequena profundidade.

O crescimento em altura para as diferentes formas de adubação, entre a primeira e a segunda (IA 2) e entre a primeira e a terceira medição (IA 3), apresentou comportamento semelhante. Em ambas, o tratamento com vermicomposto (T1) apresentou maior incremento em altura, não diferindo estatisticamente do tratamento testemunha, sem adubação, sendo diferente dos demais (Tabela 5). Os tratamentos com adubação química apresentaram os menores incrementos em altura. Menores médias de IA 3 do que no IA 2, provavelmente seja em razão das plantas podadas que foram retiradas dos cálculos dos incrementos.

A média do incremento absoluto em altura entre a primeira e a última medição apresentou o tratamento testemunha superior aos demais, não sendo estatisticamente diferente do tratamento com vermicomposto (Tabela 5). Os tratamentos 3 e 4, com adubação química, apresentaram o menor crescimento médio no período.

A diferença observada entre os tratamentos, com e sem adubação química, parece estar associado ao efeito da salinidade do adubo, prejudicando o crescimento inicial das plantas, indicando que a adubação química teve efeito contrário ao esperados o que deve estar associado ao efeito salino às raízes e a prováveis efeitos redutivos da atividade micorrízica que é intensa nessa espécie.

TABELA 5: Incremento em altura (IA) de mudas de erva-mate submetidas a diferentes formas de adubação na cova.

TABLE 5: Increment in height (IA) of erva-mate submitted to different types of fertilization in the hollow.

\begin{tabular}{lccc}
\hline Tratamentos & IA 2 $(\mathrm{cm})$ & IA 3 $(\mathrm{cm})$ & IA 4 (cm) \\
\hline T1- Vermicomposto & $21,5 \mathrm{a}$ & $22,9 \mathrm{a}$ & $31,9 \mathrm{ab}$ \\
T2- Testemunha & $20,6 \mathrm{a}$ & $22,0 \mathrm{a}$ & $32,9 \mathrm{a}$ \\
T3-1/2 Dose NPK & $15,4 \mathrm{~b}$ & $14,3 \mathrm{~b}$ & $26,4 \mathrm{bc}$ \\
T4- 1 Dose NPK & $16,3 \mathrm{~b}$ & $16,6 \mathrm{~b}$ & $24,6 \mathrm{c}$ \\
\hline
\end{tabular}

Em que: médias seguidas de mesma letra, na vertical, não diferem estatisticamente pelo teste de Duncan a $5 \%$ de probabilidade. IA 2 = Incremento entre a $1^{\mathrm{a}}$ e a $2^{\mathrm{a}}$ medição; IA $3=$ Incremento entre a $1^{\mathrm{a}}$ e a $3^{\mathrm{a}}$ medição; IA $4=$ Incremento entre a $1^{\mathrm{a}}$ e a $4^{\mathrm{a}}$ medição.

O tratamento com vermicomposto apresentou os maiores crescimentos absolutos em altura até a terceira medição, indicando que o crescimento inicial pode ser aumentado pelo vermicomposto, pois além das propriedades químicas, fonte de nutrientes, aumento da CTC, entre outras, melhora as propriedades físicas, como a maior retenção da água, fator que pode ser muito importante em períodos de estiagem e em solos arenosos. Em solos argilosos, pode agir para aumento da porosidade de aeração.

\section{Incremento em área foliar - IAF}

Os incrementos de área foliar, para os diferentes sítios, apresentaram comportamento similar. Entre a $1^{\mathrm{a}}$ e a $2^{\mathrm{a}}$ (IAF 2), a $1^{\mathrm{a}}$ e a $3^{\mathrm{a}}$ (IAF 3 ) e entre $1^{\mathrm{a}}$ e a $4^{\mathrm{a}}$ (IAF 4) medição no sítio 3 a área foliar foi o maior e no sítio 2 menor (Tabela 6).

Menor incremento na área foliar foi observado em todos os sítios no período entre a medição 2 e 3. O valor da taxa de crescimento, para o sítio 3 e 2 foi de 4,3 e $2,3 \mathrm{~cm}^{2} \mathrm{dia}^{-1}$ no período entre a $1^{\mathrm{a}}$ e $2^{\mathrm{a}}$ 
medição, 1,9 e $0,4 \mathrm{~cm}^{2}$ dia $^{-1}$ entre a $2^{\mathrm{a}}$ e a $3^{\mathrm{a}}$ medição, 4,0 e $2,8 \mathrm{~cm}^{2}$ dia $^{-1}$ entre as medições 3 e 4 respectivamente, indicando taxas de crescimentos quase duas vezes maiores no sítio 3 do que no sítio 2 . $\mathrm{O}$ sítio 1 apresentou crescimento intermediário, com IAF cerca de $75 \%$ do sítio 3.

Incremento de $984 \mathrm{~cm}^{2}$ foi observado aos 349 dias após a primeira medição para o tratamento testemunha, sendo este o maior crescimento ao final do experimento, embora não tenha tido diferença estatisticamente significativa das médias dos outros tratamentos (Tabela 7).

Entre a primeira e a segunda medição (IAF 2), houve crescimento superior no tratamento com vermicomposto, mas não foi verificada diferença significativa entre ele e os tratamentos testemunha e com $1 / 2$ dose de adubação. O menor crescimento foi verificado no tratamento T4 que não diferiu do tratamento testemunha e com $1 / 2$ dose de adubação. Entre a $1^{\mathrm{a}}$ e a $3^{\mathrm{a}}$ medição, o maior IAF foi observado no tratamento o com vermicomposto que não diferiu do tratamento testemunha. $\mathrm{O}$ crescimento menor foi verificado no tratamento com 1 dose de adubo químico, não diferindo da $1 \frac{1}{2}$ dose.

O incremento de área foliar foi superior para os tratamentos sem adubo até a terceira medição igualando-se aos com adubação 349 dias após a $1^{\text {a }}$ medição.

TABELA 6: Incremento em área foliar (IAF) de mudas de erva-mate para os sítios estudados, em três épocas de medição.

TABLE 6: Increment in foliar area (IAF) of erva-mate for the studied sites, at three times of measurement.

\begin{tabular}{c|c|c|c}
\hline Sítio & IAF 2 $(\mathrm{cm})$ & IAF 3 (cm) & IAF 4 (cm) \\
\hline 1 & $328 \mathrm{~b}$ & $421 \mathrm{~b}$ & $857 \mathrm{~b}$ \\
2 & $209 \mathrm{c}$ & $262 \mathrm{c}$ & $606 \mathrm{c}$ \\
3 & $392 \mathrm{a}$ & $645 \mathrm{a}$ & $1140 \mathrm{a}$ \\
\hline
\end{tabular}

Em que: médias seguidas de mesma letra, na vertical, não diferem estatisticamente pelo teste de Duncan a $5 \%$ de probabilidade. IAF 2 = Incremento entre a $1^{\mathrm{a}}$ e a $2^{\mathrm{a}}$ medição; IAF $3=$ Incremento entre a $1^{\mathrm{a}}$ e a $3^{\mathrm{a}}$ medição; IAF $4=$ Incremento entre a $1^{\mathrm{a}}$ e a $4^{\mathrm{a}}$ medição.

TABELA 7: Incremento em área foliar (IAF) de mudas de erva mate em função de formas de adubação.

TABLE 7: Increment in foliar area (IAF) of erva-mate in function of fertilization types.

\begin{tabular}{lcc|c}
\hline Tratamentos & IAF 2 $(\mathrm{cm})$ & IAF 3 $(\mathrm{cm})$ & IAF 4 (cm) \\
\hline T1- Vermicomposto & $341 \mathrm{a}$ & $532 \mathrm{a}$ & $888 \mathrm{a}$ \\
T2- Testemunha & $309 \mathrm{ab}$ & $493 \mathrm{a}$ & $984 \mathrm{a}$ \\
T3-1/2 Dose NPK & $289 \mathrm{ab}$ & $354 \mathrm{~b}$ & $888 \mathrm{a}$ \\
T4- 1 Dose NPK & $268 \mathrm{~b}$ & $345 \mathrm{~b}$ & $796 \mathrm{a}$ \\
\hline
\end{tabular}

Em que: médias seguidas de mesma letra, na vertical, não diferem estatisticamente pelo teste de Duncan a $5 \%$ de probabilidade. IAF 2 = Incremento entre a $1^{\mathrm{a}}$ e a $2^{\mathrm{a}}$ medição; IAF $3=$ Incremento entre a $1^{\mathrm{a}}$ e a $3^{\mathrm{a}}$ medição; IAF $4=$ Incremento entre a $1^{\mathrm{a}}$ e a $4^{\mathrm{a}}$ medição.

$\mathrm{O}$ incremento em área foliar foi um parâmetro mais sensível que o incremento em altura para diferenciação dos fatores sítio, nas condições da região de Santa Maria.

\section{Incremento em número de folhas - INF}

Em todas as medições, os sítios 1 e 3 apresentaram médias semelhantes de INF, sendo o sítio 1 superior entre a medição 1 e 2, e o sítio 3 entre a 1 e 3 e 1 e 4 (Tabela 8). Em todas as médias de incrementos, o sítio 2 foi o que apresentou o menor incremento sendo diferente significativamente dos demais, explicando o menor IAF observado nesse sítio.

Os incrementos de número de folhas entre a $1^{\mathrm{a}}$ e a $2^{\mathrm{a}}$ medição (INF 2) e entre a $1^{\mathrm{a}}$ e a $4^{\mathrm{a}}$ (INF 4 ) não diferiram entre tratamentos (Tabela 9). O maior incremento médio entre a $1^{\mathrm{a}}$ e a $3^{\mathrm{a}}$ medição foi observado no tratamento com vermicomposto, mas não diferindo significativamente dos tratamentos testemunha e com 1 dose de NPK. O tratamento com $1 / 2$ dose de NPK, nesse período, não diferiu do tratamento testemunha e 1 dose de adubo químico. No incremento entre a $1^{\mathrm{a}}$ e $4^{\mathrm{a}}$ medições, os tratamentos não apresentaram diferença significativa entre si, indicando que os tratamentos de formas de adubação para erva-mate pouco afetaram o número de folhas ou o desenvolvimento da erva-mate.

TABELA 8: Incremento em número de folhas (INF) de mudas de erva-mate para os sítios estudados em três 
épocas de medição.

TABLE 8: Increment in leaf number (INF) of erva-mate for the sites studied at three times of measurement.

\begin{tabular}{c|c|c|c}
\hline Sítio & INF2 & INF3 & INF4 \\
\hline 1 & $26 \mathrm{a}$ & $35 \mathrm{a}$ & $69 \mathrm{a}$ \\
2 & $15 \mathrm{~b}$ & $20 \mathrm{~b}$ & $46 \mathrm{~b}$ \\
3 & $23 \mathrm{a}$ & $37 \mathrm{a}$ & $82 \mathrm{a}$ \\
\hline
\end{tabular}

Em que: médias seguidas de mesma letra, na vertical, não diferem estatisticamente pelo teste de Duncan a $5 \%$ de probabilidade. INF 2 = Incremento entre a $1^{\mathrm{a}}$ e a $2^{\mathrm{a}}$ medição; INF $3=$ Incremento entre a $1^{\mathrm{a}}$ e a $3^{\mathrm{a}}$ medição; INF $4=$ Incremento entre a $1^{\mathrm{a}} \mathrm{e}$ a $4^{\mathrm{a}}$ medição.

TABELA 9: Incremento em número de folhas (INF) de mudas de rava-mate em função de formas de adubação.

TABLE 9: Increment in leaf number (INF) of erva-mate in function of fertilization types.

\begin{tabular}{lcc|c}
\hline Tratamentos & INF2 & INF3 & INF4 \\
\hline T1- Vermicomposto & $22 \mathrm{a}$ & $33 \mathrm{a}$ & $66 \mathrm{a}$ \\
T2- Testemunha & $20 \mathrm{a}$ & $32 \mathrm{ab}$ & $70 \mathrm{a}$ \\
T3-1/2 Dose NPK & $20 \mathrm{a}$ & $25 \mathrm{~b}$ & $71 \mathrm{a}$ \\
T4- 1 Dose NPK & $23 \mathrm{a}$ & $31 \mathrm{ab}$ & $66 \mathrm{a}$
\end{tabular}

Em que: médias seguidas de mesma letra, não diferem estatisticamente pelo teste de Duncan a $5 \%$ de probabilidade. INF $2=$ Incremento entre a $1^{\mathrm{a}}$ e a $2^{\mathrm{a}}$ medição; INF $3=$ Incremento entre a $1^{\mathrm{a}}$ e a $3^{\mathrm{a}}$ medição; INF $4=$ Incremento entre a $1^{\mathrm{a}}$ e a $4^{\mathrm{a}}$ medição.

\section{CONCLUSÕES}

A adubação química reduziu o número de plantas sobreviventes.

A implantação da erva-mate usando vermicomposto e sem adubo químico induziu maior crescimento inicial das plantas, medidos pelo crescimento de altura.

Houve crescimento diferente para os diferentes sítios. O sítio com solo mais raso e mais fértil, localizado nas encostas, teve maior incremento de área foliar e número de folhas.

O sítio com solo profundo, bem drenado, com textura superficial arenosa, localizado na Depressão Central, teve crescimento em área foliar cerca de $75 \%$ do melhor sítio.

\section{REFERÊNCIAS BIBLIOGRÁFICAS}

BISSO, F. P.; SALET, R.L. A erva-mate não responde a adubação fosfatada? In: REUNIÃO SUL-BRASILEIRA DE CIÊNCIA DO SOLO, 2., 1998, Santa Maria -RS. Resumos ... Santa Maria: SBCS-NRS, 1998. p.139-141.

COMISSÃO DE FERTILIDADE DO SOLO - RS/SC. Recomendação de adubação e calagem para os estados de Rio Grande do Sul e Santa Catarina. 3. ed. Passo Fundo: SBCS - Núcleo Regional Sul, 1994. 224 p.

LOURENÇO, R. S. Adubação da erva-mate. In: CONGRESSO SUL-AMERICANO DA ERVA-MATE, 2., REUNIÃO TÉCNICA DO CONE SUL SOBRE A CULTURA DA ERVA-MATE, 1., 1997, Curitiba. Anais... Curitiba: EMBRAPA, Centro Nacional de Pesquisa de Florestas, 1997. 464 p. p. 299-315. (Documentos, 33).

OLIVEIRA, Y. M. M.; ROTTA, E.. Área de distribuição natural de erva-mate. In: SEMINÁRIO SOBRE ATUALIDADES E PERSPECTIVAS FLORESTAIS: SILVICULTURA DA ERVA-MATE, 10., 1983, Curitiba. Anais... Curitiba: EMBRAPA, Centro Nacional de Pesquisa de Florestas, 1985. 145 p. p. 17-36. (Documentos, 15).

PINTRO, J. C. Efeitos de diferentes níveis de disponibilidade hídrica sobre o desenvolvimento e trocas de $\mathrm{CO}_{2}$ de plantas jovens de erva-mate (Ilex paraguariensis St. Hil.). 1986. 68p. Dissertação (Mestrado em Ciências Biológicas) - Universidade Federal do Rio Grande do Sul, Porto Alegre, 1986.

PRAT KRICUN, S. D. Yerba mate - investigación agronômica en la Republica Argentina. In: SEMINÁRIO SOBRE ATUALIDADES E PERSPECTIVAS FLORESTAIS: SILVICULTURA DA ERVA-MATE, 10., 1983, Curitiba. Anais... Curitiba: EMBRAPA, Centro Nacional de Pesquisa de Florestas, 1985. 183 p.(Documentos, 15).

SARTORI, M. da G. B.. O clima de Santa Maria, RS: do regional ao urbano. 1979. 167 p. Dissertação (Mestrado) Universidade Estadual de São Paulo, São Paulo, 1979.

Ciência Florestal, v. 13, n. 2, 2003 